\title{
The influence of recipe modification and nutritional information on restaurant food acceptance and macronutrient intakes
}

\author{
K Stubenitsky ${ }^{1,2, *}$, Jl Aaron ${ }^{1}$, SL Catt ${ }^{1,3}$ and DJ Mela ${ }^{1,4}$ \\ ${ }^{1}$ Consumer Sciences Department, Institute of Food Research, Reading RG6 6BZ, UK: ${ }^{2}$ Present address: Consumer and \\ Applications Science, New Zealand Dairy Research Institute, Palmerston North, New Zealand: ${ }^{3}$ Present address: \\ Department of Clinical Psychology, Western General Hospital, Edinburgh EH4 2X4, UK: ${ }^{4}$ Present address: \\ Consumer Science Unit, Unilever Research Vlaardingen, Vlaardingen, $3130 \mathrm{AC}$, PO Box 144, the Netherlands
}

Submitted 8 June 1998: Accepted 26 June 1999

\begin{abstract}
Objective: To examine the influences of nutritional information and consumer characteristics on meal quality expectations, food selection and subsequent macronutrient intakes of consumers offered a reduced-fat option in a restaurant.

Design: A target, full-fat (FF) main restaurant meal option was developed in a version substantially reduced in fat and energy (RF). Restaurant patrons were randomly placed into one of four treatment groups varying in provision of menu information about the target dish, and the actual version of that dish served (if ordered). A full-fat blind (FFB) control group was given no nutritional information in the menu and was served the FF version. The other three groups were all served the modified RF version: (i) reduced-fat blind (RFB), who were given no nutritional information; (ii) reduced-fat informed (RFI), who were given nutritional information; and (iii) reduced-fat informed with details (RFID), who were given the same nutritional information plus recipe modification details. Subjects rated their expected and actual liking, the pleasantness of taste, texture and appearance of the dish, how well the dish matched their expectations, and the likelihood of purchase again. Additional measures included the other dish selections, sociodemographic and attitudinal information.

Setting: A silver service (training) restaurant.

Subjects: Members of the public $(n=279)$ consuming meals in the restaurant.

Results: The presence of nutritional information on the menu did not significantly increase subsequent intakes of energy and fat from the rest of the meal, and did not significantly influence sensory expectations or post-meal acceptance measures (which also did not differ between the FF and RF versions). Consumer characteristics relating to fat reduction attitudes and behaviours were significantly related to the selection of different dishes.

Conclusions: Provision of RF alternatives in a restaurant can have significant positive dietary benefits. Menu nutritional information did not affect measures of meal acceptance. Further studies should identify which types of information formats might be most effective in enhancing the selection of 'healthy' options.
\end{abstract}

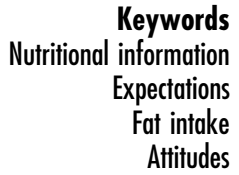

Research has shown that the number of meals eaten outside the home and the expenditure on these are increasing in many countries ${ }^{1,2}$. In the UK in 1995, average daily energy intake from eating out was equivalent to just over $11 \%$ of energy intake for all sources, with the proportion of energy derived from fat and saturated fatty acids being higher from food eaten out ( $41.8 \%$ and $16.4 \%$, respectively) than from household food (38.2\% and $15.2 \%$, respectively) ${ }^{2}$. Foods contributing most to both energy and fat intake were meat, potatoes, vegetables and salads, i.e. common major components of many typical British main meal dishes ${ }^{2}$. These data suggest that eating out in restaurants or catering situations can have a large and direct impact on total macronutrient intake. Examples of 'healthy eating' guidelines have been suggested for the restaurant and catering industry, along with proposals for systems for these outlets to assist customers in making food choices based upon nutritional criteria ${ }^{3}$.

There have been a number of studies of strategies encouraging people to choose a 'healthy' or 'reduced-fat' option in catering or supermarket situations ${ }^{4-10}$, and although in general these interventions have been successful in terms of establishing more positive attitudes towards target foods, the effects on purchase behaviour and sales (especially in the long term) has been mixed. Other studies have focused on understanding the effects of different 
formats for nutritional information in general or at the point of purchase $\mathrm{e}^{11,12}$, or the interactions of information with consumer characteristics ${ }^{13-16}$. However, such formats typically provide only objective, absolute information on nutrition, whereas it is common for catering sites and product packaging to combine health-related information or claims with other product descriptors (e.g. regarding ingredients or sensory quality).

A small number of studies have looked at the general influences of nutritional information and formats on the acceptance and intake of 'healthy' alternatives in a catering situation ${ }^{17,18}$. This work suggests that the effect of nutritional labelling might not necessarily be positive (e.g. in terms of fat or energy intakes), and may even have a negative effect on food choice, at least in certain subject groups and situations. Other recent studies in the consumer science field have highlighted the important role of characterizing consumer subgroups by their attitudinal characteristics, information which may explain differential responses to provision of information on, for example, acceptance and intake of reduced-fat products ${ }^{19-26}$.

Several studies have suggested that specific information about foods, such as highlighting of 'healthy' or 'reducedfat' attributes, may influence consumer expectations and thereby acceptance ${ }^{27-35}$. A food which is claimed to be 'gourmet' but which does not meet consumer's expectations may well be judged to be less liked than (objectively comparable but) less acclaimed food that does meet expectations, a general outcome confirmed by numerous studies $^{27-35}$.

Nutritional and sensory descriptive information about 'healthy' or 'low-fat' options, and its interactions with the attitudes and prior expectations of consumers in a restaurant, may clearly affect acceptance and satisfaction with the meals, as well as overall dietary intake. These raise important issues with regard to achieving economically successful and nutritionally beneficial changes within the catering environment. The present study therefore specifically examines the influences of menu information, dish modification and attitudinal characteristics on expectations, acceptance and subsequent energy and fat intake in a restaurant.

\section{Methods}

This study was carried out during 2 weeks in June and October 1996 in the training restaurant of a hotel school. Subjects $(n=279)$ were members of the public who made bookings for a meal at the restaurant during the week in which the study was being held. They were informed by members of staff that a study was being carried out that week, which would involve filling in some questionnaires before and after having their meal, and that the purpose of this was to look at customer preferences and food quality. In return, their meal would be free. Because the restaurant is used for training students as part of their vocational qualifications course work, questionnaires of this nature would not be unusual or unexpected. The protocol was approved by the Institute of Food Research Human Research Ethics Committee, and subjects read and signed a brief consent form before their meal.

The menu, as normal for this restaurant, consisted of a choice of three starters, three main courses, a selection of vegetables, and three desserts. Recipe details, including portion sizes were obtained from the chef for all dishes. The nutritional composition of each dish was calculated using a PC-based dietary analysis software (CompEat 4, Lifeline Nutrition Services Ltd, London) and this information is presented in Table 1.

Table 1 Nutritional composition of the menu options (per portion)

\begin{tabular}{|c|c|c|c|c|c|}
\hline \multirow[b]{2}{*}{ Food items } & \multicolumn{2}{|c|}{ Energy } & \multirow{2}{*}{$\begin{array}{l}\text { Protein } \\
\text { (en\%) }\end{array}$} & \multirow{2}{*}{$\begin{array}{c}\text { Fat } \\
(e n \%)\end{array}$} & \multirow{2}{*}{$\begin{array}{c}\text { Carbohydrate } \\
(\text { en\%) }\end{array}$} \\
\hline & kcal & kJ & & & \\
\hline \multicolumn{6}{|l|}{ Starters } \\
\hline Cream of asparagus soup & 430 & 1777 & 3.3 & 85.1 & 12.3 \\
\hline Parsnip and apple soup & 314 & 1306 & 3.7 & 66.6 & 31.7 \\
\hline Prawns with lime and ginger & 166 & 691 & 16.2 & 60.8 & 23.7 \\
\hline Nicoise salad & 141 & 590 & 9.8 & 61.0 & 31.6 \\
\hline \multicolumn{6}{|l|}{ Main courses } \\
\hline Smoked haddock with Welsh rarebit (full fat) & 580 & 2404 & 26.0 & 69.7 & 4.2 \\
\hline Smoked haddock with Welsh rarebit (reduced fat) & 265 & 1112 & 60.8 & 29.9 & 10.1 \\
\hline Stir fry beef with mushrooms & 273 & 1144 & 38.7 & 44.2 & 17.9 \\
\hline Pasta alicia & 800 & 3390 & 11.4 & 31.2 & 61.3 \\
\hline \multicolumn{6}{|l|}{ Side dishes } \\
\hline Flemish style peas and buttered carrots & 346 & 1440 & 20.8 & 38.7 & 43.1 \\
\hline Stuffed tomatoes & 150 & 626 & 9.1 & 65.7 & 28.1 \\
\hline Sautee potatoes & 192 & 798 & 4.4 & 61.9 & 35.8 \\
\hline Byron potatoes & 199 & 833 & 11.8 & 38.7 & 52.4 \\
\hline \multicolumn{6}{|l|}{ Desserts } \\
\hline Queen of puddings & 338 & 1419 & 10.8 & 27.6 & 65.7 \\
\hline Poached pears in red wine and cornets & 623 & 2604 & 3.6 & 31.5 & 65.4 \\
\hline Chocolate mousse & 497 & 2068 & 7.6 & 66.5 & 27.7 \\
\hline
\end{tabular}




\section{Disb modification}

For this study, one main dish (smoked haddock with welsh rarebit) was selected as the 'target' item for manipulations of composition and menu information. The two other main dishes were stir fry beef and vegetarian pasta alicia (Table 1). Dishes are normally presented only by name on the menu, and this was always the case for all of the non-target dishes in this trial. As usually prepared, the target dish had the highest energy content and per cent energy from fat of all main course non-vegetarian options (2.4 MJ and $70 \mathrm{en} \%$ fat per serving), but it could be relatively easily produced as an acceptable RF version (1.1 MJ and 30 en\% fat per serving) using reduced-fat cheese and skimmed milk, and leaving an oily vinaigrette dressing out of the dish. The appearance of the FF and RF dishes were similar to each other, and they were not readily distinguished in a pilot sensory test trial with 15 restaurant customers, who did not take part in the main study.

\section{Menu information}

Subjects seated in different parts of the restaurant were presented with printed menus differing only in the descriptive information accompanying the target dish. In two test treatments, subjects were given no additional information (i.e. dish name alone), and these subjects then actually received (blind) either the FF or RF version of the target dish; in two further treatments, subjects were truthfully informed of the lower fat content of the RF target dish (with or without further preparation details), and served this version. The four treatment groups were therefore:

1. Full-fat blind (FFB): no additional information (FF version served).

2. Reduced-fat blind (RFB): no additional information (RF version served).

3. Reduced-fat informed (RFI): 'This is a lower fat option' (RF version served).

4. Reduced-fat informed with details (RFID): 'This lower fat option is prepared with reduced-fat cheese and skimmed milk' (RF version served).

Subjects were unaware of the alternative printed versions of the menu or versions of the target dish.

\section{Questionnaires}

\section{Before the meal}

After ordering and before the meal was served, all subjects were asked to fill in a questionnaire, worded in the form: 'Shortly you will be presented with a serving of (main meal option chosen). For each of the following questions, please place a tick in the box which best describes your opinion.' Questions were answered on nine-point category scales, and subjects were asked how much they expected to like the dish (from 'dislike extremely' to 'like extremely'), how pleasant they expect the taste, texture and appearance to be (from 'not at all pleasant' through 'extremely pleasant'), how beneficial they thought eating this dish would be for their health (from 'not at all beneficial' through 'extremely beneficial') and how hungry they were (from 'not at all hungry' to 'extremely hungry').

\section{After the meal}

The same questions were asked after finishing their meal, but worded in such a way which related to their actual perception of the meal which had just been eaten. In addition, subjects were asked how well their meal had matched their expectations ('did not match my expectations at all' through 'matched my expectations perfectly'), how good the dish was relative to that expected ('far worse than expected' through 'far better than expected') and how likely it was that they would purchase the dish again on another occasion ('extremely unlikely to purchase' through 'extremely likely to purchase').

\section{Final questionnaire}

A final questionnaire regarding attitudes and beliefs towards eating 'healthy options' in a catering environment was completed following the entire meal. It included questions regarding demographic characteristics, a question which assessed restrained eating behaviour (adapted from the restrained eating scale of the Dutch Eating Behaviour Questionnaire ${ }^{36}$ ), the frequency of eating RF foods (never/seldom/sometimes/often/very often), the frequency of eating out (once per month/about 1-3 times per month/about once a week/ $>1$ time per week) and whether eating out was part of a normal daily or weekly routine (yes daily/yes weekly/no).

Subjects' attitudes and beliefs were assessed using questions adapted from the theory of planned behaviour $^{37}$. In this model, behaviour is viewed as primarily predicted by someone's intention to perform that behaviour, which in turn is predicted by individual attitudes (favourable or unfavourable) towards the behaviour, other people's influences towards performing the behaviour (subjective norm) and the control people feel they have over the behaviour (perceived behavioural control). Attitudes are predicted as the result of the consequences people expect from the behaviour (beliefs) and the way people value those expected consequences (the importance of the belief). Attitudes are thus quantitatively determined as the sum of measures of a set of relevant beliefs (e.g. the extent to which eating a given food is believed to reduce heart disease risk) weighted by the corresponding evaluation of these beliefs (e.g. the perceived importance of eating foods which reduce heart disease risk).

Attitude was assessed by asking 'My attitude towards choosing a healthy option for a meal is ...' on a seven-point scale from 'extremely unfavourable' to 'extremely favourable'. Behavioural beliefs were assessed by asking 'How 
much do you agree or disagree with the following statement? - When eating out, choosing a healthy option for a meal means choosing foods which: are nutritious/are tasty/are of good quality/have a healthy fat content/are good for my health/help to control my weight/are filling/are value for money/are expensive/fit in with my other meals of the day/I always feel like eating', all on seven-point category scales from 'disagree strongly' to 'agree strongly'. Corresponding outcome evaluation questions were worded identically, but answered on seven-point category scales from 'extremely unimportant' to 'extremely important', to assess the value of the expected consequences (the importance of the behavioural beliefs). Intention towards choosing a healthy option when eating out was assessed by asking 'When eating out, how likely is it that you would choose a healthy option for a meal if it was provided next to traditional menu items', on a seven-point category scale from 'extremely unlikely' to 'extremely likely'.

Further questions were derived from the 'stage of change' model of Prochaska ${ }^{38}$, which proposes that health-related behavioural changes occur through a series of five stages: precontemplation (unaware or not thinking about making a change), contemplation (seriously thinking about changing), decision or preparation (making definite plans to change), action (actively modifying an unhealthy behaviour) and maintenance (maintaining the new favourable behaviour for a period of time). Glanz et $a l .{ }^{39}$ adapted the model successfully to food-related behaviour, and provided the example upon which the question here was based. Subjects were asked which best described their thoughts about choosing a healthy option when eating out to assess the current stage they were in. The response options were: 'I have never thought about and am not interested in choosing a healthy option for a meal when I am eating out (stage 1)', 'I should choose a healthy option for a meal when I am eating out, but have rarely or never done so (stage 2)'; 'I usually try to choose a healthy option for a meal when I am eating out (stage 3)'; and 'I have chosen a healthy option for a meal in the past when I was eating out, but do not do so now (stage 4)'. Additional questions elicited the reasons why stage 1 subjects did not try to choose a healthy option for a meal when eating out.

\section{Data analyses}

Statistical analyses were carried out using SPSS (version 6.1, SPSS Inc., Chicago), and data are described as mean $( \pm$ SEM) unless otherwise noted. A value of $P<0.05$ was used as a criterion for statistical significance. Except as noted, chi-square analysis was used for comparisons of categorical data, and one-way analysis of variance (ANOVA) for between-groups comparisons of continuous data (data from seven- and nine-point rating scales are generally treated as continuous). Where overall ANOVAs were significant, a Student-Newman-Keuls test was used for post hoc multiple comparisons.
A full-factorial two-way ANOVA was used to assess main and interactive effects of meal choice and information condition on total intakes of energy and fat.

Attitude, behaviour belief items and behavioural intention were scored from 1 to 7 , and corresponding outcome evaluation items were scored from -3 to +3 . Each belief response $(b)$ was multiplied by the corresponding evaluation score $(e)$ and the products summed over every belief item $(\Sigma b \cdot e)$ using the procedure of Fishbein and Ajzen ${ }^{40}$.

\section{Results}

\section{Sociodemographic data}

Other than a somewhat older than average age, the sociodemographic characteristics of the subject population were typical of the UK population as a whole, and were not significantly different between the four treatment groups for subjects who chose the haddock dish (Table 2). Although there was an overall age effect for most of the outcome measures (subjects in the older age groups differed in absolute terms from those in the younger age groups), this did not significantly influence the direction of any of the outcome measures.

\section{Influence of information and dish choice on macronutrient intakes}

Amongst subjects choosing the target haddock dish, treatment had a significant influence on total energy and grams of fat intake only for the FFB group $(F(3,80)=5.27$, $P=0.002$ and $F(3,80)=13.82, P<0.001$, respectively) (Fig. 1). This effect directly reflected the actual difference in energy and grams of fat between the $\mathrm{FF}$ and $\mathrm{RF}$ dish. There were no significant influences of menu information on grams of fat and energy intake for subjects selecting the stir fry beef dish and the pasta dish. Subjects in the FFB group had the highest intake of grams of fat and energy of all treatment dish selection combinations. Amongst the three groups receiving the RF target dish, menu information had no effect on total energy and fat intake.

\section{Influence of menu information on main meal disb choice}

Overall, and in every group, more consumers selected the beef dish than the target haddock or the pasta dish $(P<$ 0.05) (Table 3 ). The proportion of subjects choosing the haddock dish was not significantly higher when no information was presented (two control groups, 49 out of $139=35 \%$ of subjects) versus when the RF version was identified by nutritional information alone or with modification details (35 out of $140=25 \%)(P=0.151)$. The proportion of subjects choosing the stir fry beef or the vegetarian pasta dish was not influenced by the presence of information on the menu $(P>0.05)$. 
Table 2 Demographic characteristics of the subjects $(n=279)$

\begin{tabular}{|c|c|}
\hline Characteristics & $\%$ \\
\hline \multicolumn{2}{|l|}{ Age (years) } \\
\hline $16-24$ & 6.9 \\
\hline $25-34$ & 4.7 \\
\hline $35-49$ & 22.8 \\
\hline $50-64$ & 25.0 \\
\hline $65+$ & 40.6 \\
\hline \multicolumn{2}{|l|}{ Gender } \\
\hline Male & 32.1 \\
\hline Female & 67.9 \\
\hline \multicolumn{2}{|l|}{ Marital status } \\
\hline Single & 15.2 \\
\hline Married & 69.2 \\
\hline Living as married & 4.7 \\
\hline Widow/er & 10.9 \\
\hline \multicolumn{2}{|l|}{ Social class* } \\
\hline$A$ & 10.9 \\
\hline B & 44.5 \\
\hline $\mathrm{C}$ & 28.3 \\
\hline $\mathrm{D}$ & 3.8 \\
\hline $\mathrm{E}$ & 1.1 \\
\hline Student & 1.1 \\
\hline Retired & 9.1 \\
\hline \multicolumn{2}{|l|}{ Body mass index $\left(\mathrm{kg} \mathrm{m}^{-2}\right)$} \\
\hline$<20$ & 9.0 \\
\hline $20-30$ & 77.4 \\
\hline$>30$ & 13.6 \\
\hline \multicolumn{2}{|l|}{ Medical or other diet } \\
\hline Yes, at this moment & 14.3 \\
\hline No, but was in the past & 30.0 \\
\hline Never have been on a diet & 55.7 \\
\hline \multicolumn{2}{|l|}{ Vegetarian } \\
\hline No & 97.0 \\
\hline Yes & 3.0 \\
\hline \multicolumn{2}{|c|}{ Number of adults in the house } \\
\hline 1 & 22.5 \\
\hline 2 & 61.4 \\
\hline$>2$ & 16.1 \\
\hline
\end{tabular}

${ }^{*} \mathrm{~A}$, higher managerial or professional; B, lower managerial; C, skilled nonmanual and non-skilled manual; D, partially skilled manual; E, unskilled (Office of Population Censuses and Surveys, 1980).

\section{Pre-meal (expectation) and post-meal (actual) ratings}

Although there were a number of significant differences in pre-meal (expectation) ratings between the four treatment groups for subjects who chose the haddock dish, these differences did not form a consistent pattern (Table 4). The FFB group had a significantly lower expected liking, taste and texture rating than the other three groups $(F(3,80)=$ $3.98, F(3,80)=6.52$ and $(F(3,80)=3.9$, respectively; all $P<0.05)$. Amongst subjects choosing the haddock dish, there were no significant treatment effects on: (i) postmeal (actual) ratings, (ii) between pre-meal (expected) and post-meal (actual) ratings (Table 4), (iii) direct confirmation/disconfirmation ratings, and (iv) likelihood to purchase again ratings (Table 5).

\section{Attitudes and beliefs}

In the total subject population, there was a slightly positive attitude towards choosing healthy options when eating out (overall mean \pm SEM $4.8 \pm 0.2, P<0.05$ vs scale midpoint of 4), although there were no significant differences in attitude ratings between the four treatment groups or between each of the dish groups (data not shown). However, there were a number of significant differences in belief $\times$ evaluation $(b \cdot e)$ scores amongst subjects selecting the different menu items. The general
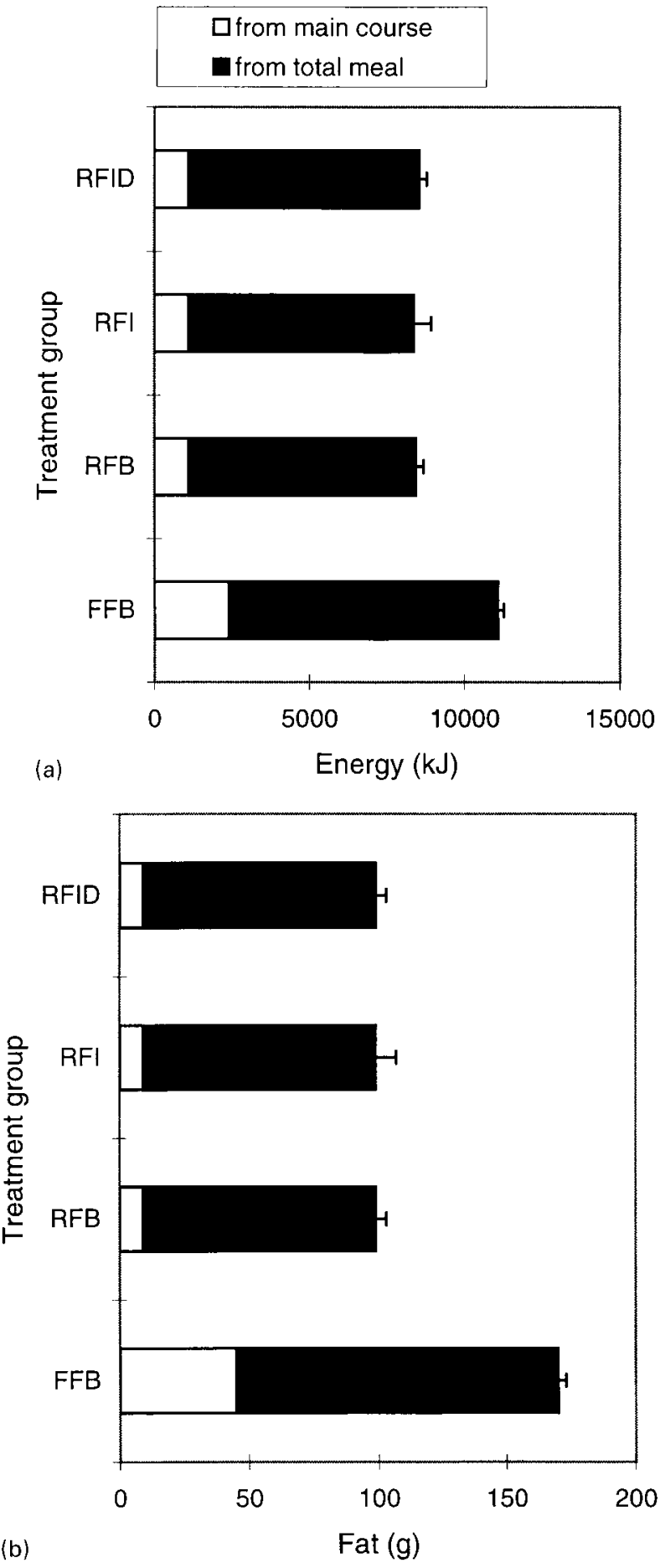

Fig. 1 Total meal and main course energy (a) and fat intake (b) by treatment group (mean \pm SEM). Data for subjects choosing target dish only 
Table 3 Percentage (number) of subjects choosing each main course option

\begin{tabular}{lcccr}
\hline Treatment group & $\begin{array}{c}\text { Smoked haddock and } \\
\text { Welsh rarebit }\end{array}$ & Stir fry beef & Pasta alicia & Total \\
\hline Full-fat blind & $38(26)^{\mathrm{a}}$ & $46(32)^{\mathrm{a}}$ & $16(11)^{\mathrm{bc}}$ & $(69)$ \\
$\begin{array}{l}\text { Reduced-fat blind } \\
\text { Reduced-fat informed }\end{array}$ & $33(23)^{\mathrm{a}}$ & $54(38)^{\mathrm{a}}$ & $13(9)^{\mathrm{ac}}$ & $(70)$ \\
$\begin{array}{l}\text { Reduced-fat informed with } \\
\text { modification details }\end{array}$ & $26(18)^{\mathrm{a}}$ & $71(49)^{\mathrm{a}}$ & $3(2)^{\mathrm{a}}$ & $(69)$ \\
Total & $24(17)^{\mathrm{a}}$ & $51(36)^{\mathrm{a}}$ & $25(18)^{\mathrm{b}}$ & $(71)$ \\
\hline
\end{tabular}

$\overline{a, b, c}$ Column values not sharing a common superscript indicate a significant group difference in the proportion of subjects selecting that main course option $(P<0.05)$.

Table 4 Mean \pm SEM pre-meal (expectation) and post-meal (actual) ratings ${ }^{*}$ amongst the treatment groups for the target dish (smoked haddock with Welsh rarebit)

\begin{tabular}{|c|c|c|c|c|c|c|c|}
\hline \multirow[b]{2}{*}{ Treatment group } & \multirow[b]{2}{*}{$n$} & \multicolumn{2}{|c|}{ Liking of the dish } & \multicolumn{2}{|c|}{ Pleasantness of taste } & \multicolumn{2}{|c|}{ Pleasantness of texture } \\
\hline & & Pre & Post & Pre & Post & Pre & Post \\
\hline Full-fat blind & 26 & $7.3 \pm 0.2^{a}$ & $7.5 \pm 0.3^{a}$ & $7.3 \pm 0.3^{a}$ & $7.4 \pm 0.3^{a}$ & $7.3 \pm 0.3^{a}$ & $7.6 \pm 0.3^{a}$ \\
\hline Reduced-fat blind & 23 & $8.3 \pm 0.2^{b}$ & $8.4 \pm 0.3^{\mathrm{a}}$ & $8.7 \pm 0.1^{\mathrm{b}}$ & $8.6 \pm 0.2^{b}$ & $8.3 \pm 0.2^{b}$ & $8.1 \pm 0.2^{\mathrm{a}}$ \\
\hline Reduced-fat informed & 18 & $8.1 \pm 0.3^{b}$ & $8.3 \pm 0.2^{\mathrm{a}}$ & $8.2 \pm 0.2^{b}$ & $8.3 \pm 0.2^{b}$ & $7.9 \pm 0.2^{\mathrm{a}}$ & $7.9 \pm 0.3^{\mathrm{a}}$ \\
\hline $\begin{array}{l}\text { Reduced-fat informed } \\
\text { with modification details }\end{array}$ & 17 & $8.2 \pm 0.3^{b}$ & $7.8 \pm 0.4^{a}$ & $8.3 \pm 0.3^{b}$ & $8.2 \pm 0.3^{b}$ & $8.2 \pm 0.3^{b}$ & $8.3 \pm 0.3^{a}$ \\
\hline
\end{tabular}

${ }^{*}$ Range from 1 to 9 , midpoint $=5$.

${ }^{a}, \mathrm{~b}$ Column values not sharing a common superscript are significantly different $(P<0.05)$. Pre-meal scores are not significantly different from post-meal scores.

Table 5 Mean \pm SEM direct confirmation/disconfirmation ratings and likelihood to purchase* amongst the treatment groups for the target dish (smoked haddock with Welsh rarebit)

\begin{tabular}{lcccc}
\hline Treatment group & $n$ & $\begin{array}{c}\text { How well did the dish } \\
\text { match expectations? }\end{array}$ & $\begin{array}{c}\text { How good was the dish } \\
\text { relative to expected? }\end{array}$ & $\begin{array}{c}\text { Likelihood } \\
\text { to purchase }\end{array}$ \\
\hline Full-fat blind & 26 & $7.4 \pm 0.4$ & $6.5 \pm 0.4$ & $6.8 \pm 0.5$ \\
Reduced-fat blind & 23 & $8.3 \pm 0.3$ & $6.2 \pm 0.3$ & $7.7 \pm 0.4$ \\
Reduced-fat informed & 18 & $7.6 \pm 0.6$ & $6.1 \pm 0.4$ & $8.1 \pm 0.4$ \\
Reduced-fat informed & 17 & $8.1 \pm 0.3$ & $6.2 \pm 0.4$ & $7.4 \pm 0.5$ \\
$\quad$ with modification details & & & & \\
\hline
\end{tabular}

${ }^{*}$ Range from 1 to 9 , midpoint $=5$. No significant differences between groups.

trend was for subjects who chose the haddock and pasta dishes to be more concerned with their health than those who chose the beef dish, but only in the RFI treatment group (data not shown).

\section{Stage of change}

There were no significant differences in the proportion of subjects in each stage of change amongst subjects selecting the different main course options within each subject group (data not shown), although the proportion of subjects who chose the haddock and pasta dishes were in general in later stages of change ('should choose' or 'usually try to choose a healthy option for a meal when eating out') than people who chose the beef dish, who were mainly in the first stage of change ('have never thought about' or 'am not interested in choosing a healthy option for a meal when eating out'). The main reason for not being interested in trying to choose a healthy option when eating out (stage 1), was that subjects felt that eating out was a special occasion on which they would allow themselves to eat anything.
Influence of attitudinal characteristics and stage of change on pre-meal (expectation) and post-meal (actual) ratings

There were no significant differences in pre-meal (expectation) and post-meal (actual) ratings for the haddock dish between subjects with a favourable and an unfavourable attitude (data not shown). However, subjects in stage 2 and 3 of behavioural change ('should choose' or 'usually try to eat a healthy option when eating out') had overall significantly higher post-meal (actual) liking ratings than those in stage 1 of behavioural change ('am not interested in choosing a healthy option when eating out'), and were more likely to purchase again (mean liking \pm SEM $8.14 \pm 0.16$ vs $7.54 \pm 0.34$, respectively; $F(1,77)=4.19, \quad P=0.04 ;$ mean likelihood to purchase again \pm SEM $7.89 \pm 0.24$ vs $6.29 \pm 0.58$, respectively; $F(1,78)=9.07, P=0.004)$.

\section{Discussion}

The presence of factual 'lower fat' information did not substantially affect expectations of sensory quality and 
acceptance, or overall energy and fat intake, though it was associated with a trend toward a decreased proportion of restaurant patrons selecting the target dish. In addition, behavioural characteristics such as attitude, beliefs and stage of change were significantly related to selection of the target RF dish.

We did not find, in contrast to some other studies, differences in overall meal fat and energy intake of subjects informed versus not informed of the lower fat content of their main course dish (i.e. RFI vs RFB). Caputo and Mattes ${ }^{41}$ reported that subjects falsely informed that they were given lower fat lunches (in a laboratory), increased their freely chosen intakes of energy and fat (outside the laboratory) relative to periods when different information was given. Chapelot et al. ${ }^{42}$ showed that nonrestrained eaters had relatively increased energy intakes when a low-fat dish was identified as such, and we previously found that some subjects increased their fat and energy intake when relevant nutritional information was presented at point of purchase in a cafeteria ${ }^{18}$. The present results are, however, analogous to those of Dubbert et $a l{ }^{43}$, who did not find an effect of low-calorie labelling on the total caloric content of meals chosen, although they observed an increase in the selection of higher calorie entrees. It appears likely that at least for some consumers, and in certain situations, there may be cognitively based compensation for consumption of meals perceived to have lower fat or energy contents. There is little evidence for physiological compensation within a meal when higher fat items are covertly replaced by lower fat alternatives $^{44-48}$. This was certainly true in the present study: subjects blindly given the full-fat version of the main course dish (group FFB) had substantially greater total (including main course) meal intakes of energy and fat than their counterparts (RFB group) served the lower fat version, with these differences directly reflecting the quantitative differences between the FF and the RF dishes.

Provision of menu information did not have a significant effect on pre-meal expectation ratings. Several other studies ${ }^{17,21,27,33-35}$ have found negative expectation effects of nutrition or health labels; however, the present results are in agreement with a separate study we have run using similar menu information and restaurant setting ${ }^{49}$. In that study, measures of expectation and acceptance were also not significantly different between the treatments with or without nutritional information on the menu. In addition, Köster et al. ${ }^{50}$ found that people who were given health information with a 'healthy' snack were more positive in post-meal hedonic responses and purchase behaviour than people who received no health information with the snack.

The present results show that attitudinal characteristics such as beliefs and stage of change towards trying to choose a healthy option when eating out, had a significant relationship with the selection of main course dish. In addition, other indirect attitude measures, such as the frequency of eating reduced-fat or reduced-sugar foods, were significantly related to attitude, intention to try to chose a healthy option when eating out, and stage of change, thereby confirming the importance of psychological influences on menu selection. Similar results were found in a study of Aaron et al. ${ }^{19}$, in which consistent interactive effects of label information were found with consumer attitudes, beliefs and (to a lesser degree) with the type of product normally used; and by Tuorila et $a l .^{35}$, where the acceptance of a new product was affected by various factors which operated on their own (such as age) or in combination with other product, consumer or context based variables (e.g. type of information, flavour, food neophobia).

Subjects in this study tended to be older than average, and this may have had some influence on the results, although the direction of the outcome measures were the same in all age groups. Most of the subjects were also regular visitors of the restaurant, and this may underlie their uniformly high pre-meal expectations, based on prior personal experience. In addition, the nutritional calculations were only based on the amount and type of food served, and practical considerations meant that it was not possible to measure left-overs. This would have enhanced the accuracy of the actual intake data, though the effect would be expected to be small compared to that observed for meal composition.

\section{Conclusions}

Provision of an acceptable lower fat, lower energy main course dish in a restaurant setting had a direct effect on fat and energy intake, which was not compensated for in other components of the meal, and was not affected by consumer knowledge of the 'lower fat' nature of the dish (through menu text). Measures of meal expectations, actual acceptance and perceived matching of expectations were also not affected by this information. These results, and that of a previous study ${ }^{49}$, suggest that this is an approach which could be successfully used, with dietary benefits and good consumer acceptance. However, we also observed a trend toward lower selection of the lower fat dish amongst subjects informed of its lower fat status, and therefore care may need to be taken with implementation of such menu information in practice. Further studies should identify which types of information formats might be most effective in enhancing the selection of 'healthy' options.

\section{Acknowledgements}

This project has been funded by the Commission of the European Communities as part of project FAIR-CT95-0574 and the Biotechnology and Biological Sciences Research Council. The authors would like to thank all staff at the Norwich City College Hotel School for their help. 


\section{References}

1 Moody R. Nutritional information: do we know what we are eating? Proc. Nutr. Soc. 1992; 51: 55-61.

2 Ministry of Agriculture, Fisheries and Food. National Food Survey 1995. London: HMSO, 1995.

3 Department of Health. Eat Well! An Action Plan from the Nutrition Task Force to Achieve the Health of the Nation Targets on Diet and Nutrition. London: Department of Health, 1994.

4 Almanza BA, Mason APC, Widdows R, Girard FJ. Consumer responses to nutrition guidelines labelling in a university restaurant. J. Am. Diet. Assoc. 1993; 93(5): 580-1.

5 Balfour D, Moody R, Wise A, Brown K. Food choice in response to computer generated nutrition information provided about meal selections in work place restaurants. J. Hum. Nutr. Diet. 1996; 9: 231-7.

6 Hunt MK, Lefebre C, Hixon ML, Banspach SW, Assaf A, Carleton RA. Pawtucket heart health program point-ofpurchase nutrition education program in supermarkets. $\mathrm{Am}$. J. Public Health 1990; 80(6): 730-2.

7 Levin S. Pilot study of a cafeteria program relying primarily on symbols to promote healthy choices. Soc. Nutr. Educ. 1996; 28(5): 282-5.

8 Lidell JA, Lockie GM, Wise A. Effects of a nutrition education programme on the dietary habits of a population of students and staff at a centre for higher education. J. Hum. Nutr. Diet. 1992; 5: 23-33.

9 Perlmutter CA, Canter DD, Gregoire MB. Profitability and acceptability of fat- and sodium-modified hot entrees in a worksite cafeteria. J. Am. Diet. Assoc. 1997; 97: 391-5.

10 Whitaker RC, Wright JA, Finch AJ, Pasty BM. An environmental intervention to reduce dietary fat in school lunches. Pedriatics 1993; 91(6): 1107-11.

11 Albright CL, Flora JA, Fortmann SP. Restaurant menu labelling: impact on nutritional entree sales and patron attitudes. Health Educ. Q. 1990; 17(2): 157-67.

12 Fullmer S, Grieger CJ, Parent CRM. Consumers knowledge, understanding and attitudes towards health claims on food labels. J. Am. Diet. Assoc. 1991; 91(2): 166-71.

13 Cole CA, Catherine A, Gaeth GJ. Cognitive and age-related differences in the ability to use nutritional information in a complex environment. J. Market. Res. 1990; 27: 175-84.

14 Guthrie JF, Fox JJ, Cleveland LE, Welsh S. Who uses nutrition labelling, and what effects does label use have on diet quality? J. Nutr. Educ. 1995; 27(4): 163-72.

15 Moorman C. The effects of stimulus and consumer characteristics on the utilisation of nutritional information. J. Consumer Res. 1990; 17: 362-74.

16 Hunt MK, Stoddard AM, Glanz K, et al. Measures of food choice behavior related to intervention messages in worksite health promotion. J. Nutr. Educ. 1997; 29(3): 3-11.

17 Colby JJ, Elder JP, Peterson G, Knisley PM, Carleton RA. Promoting the selection of healthy food through menu item description in a family-style restaurant. Am. J. Prev. Med. 1987; 3: 171-7.

18 Aaron JI, Evans RE, Mela DJ. Paradoxical effect of a nutrition labelling scheme in a student cafeteria. Nutr. Res. 1995; 15(9): 1251-61.

19 Aaron JI, Mela DJ, Evans RE. The influences of attitudes, beliefs and label information on perceptions of reduced-fat spread. Appetite 1994; 22: 25-37.

20 Daillant-Spinnler B, Issanchou S. Influence of label and location of testing on acceptability of cream cheese varying in fat-content. Appetite 1995; 24(2): 101-5.

21 Engell D, Bordi P, Borja M, Lambert C, Rolls B. Effects of information about fat content on food preferences in preadolescent children. Appetite 1995; 30: 269-82.

22 Helleman U, Tuorila H, Matuszewska I, Lampi AM. Hedonic responses and attitudes related to fast used as spreads on bread. Food Qual. Pref. 1990; 2: 29-38.

23 Kähkönen P, Tuorila H, Rita H. How information enhances acceptability of a low-fat spread. Food Qual. Pref. 1996; 7(2): 87-94.

24 Kähkönen P, Tuorila H, Lawless H. Lack of effect of taste and nutrition claims on sensory and hedonic responses to a fatfree yoghurt. Food Qual. Pref. 1997; 8(2): 125-30.

25 Solheim R, Lawless HT. Consumer purchase probability affected by attitude towards low-fat foods, liking, private body consciousness and information on fat and price. Food Qual. Pref. 1996; 7(2): 137-43.

26 Westcombe A, Wardle J. Influence of relative fat content information on responses to three foods. Appetite 1997; 28 49-62.

27 Cardello AV, Sawyer FM. Effects of disconfirmed consumer expectations on food acceptance. J. Sensory Studies 1992; 7: 253-77.

28 Cardello AV. Consumer expectations and their role in food acceptance. In: MacFie HJM, Thompson DMH, eds. Measurement of Food Preferences. London: Blackie, 1994; 254-97.

29 Cardello AV, Bell R, Kramer FM. Attitudes of consumers toward military and other institutional foods. Food Qual. Pref. 1996; 7(1): 7-20.

30 Engell D, Bordi P, Borja M, Lambert C, Rolls B. Effects of information about fat content on consumers' acceptance and sensory ratings of cookies. Food Qual. Pref. 1996; 7(3/ 4): (special issue) 2nd Rose Marie Pangborn Memorial Symposium Proceedings: 305-53. Abstracts.

31 Kähkönen P, Tuorila H. Lack of reduced-fat information on expected and actual hedonic and sensory ratings of sausage. Appetite 1998; 30: 13-23.

32 Solheim R. Consumer liking for sausages affected by sensory quality and information of fat content. Appetite 1992; 19: 285-92.

33 Tuorila H, Meiselman HL, Bell R, Cardello AV, Johnson W. Role of sensory and cognitive information in the enhancement of certainty and liking for novel and familiar foods. Appetite 1994; 23: 231-46.

34 Tuorila H, Cardello AV, Lesher LL. Antecedents and consequences of expectations related to fat-free and regular-fat foods. Appetite 1994; 23: 247-64.

35 Tuorila H, Andersson A, Martikainen A, Salovaara H. Effect of product formula, information and consumer characteristics on the acceptance of a new snack food. Food Qual. Pref. 1998; 9(5): 313-20.

36 Van Strien T, Frijters JER, Bergers GPA, Defares PB The Dutch Eating Behaviour Questionnaire (DEBQ) for assessment of restrained, emotional and external eating behaviour. Int. J. Eating Disorders 1986; 5: 295-315.

37 Ajzen I. From intentions to action: a theory of planned behaviour. In: Kuhle J, Beckman J, eds. Action Control: from Cognition to Behaviour. Heidelberg: Springer Verlag, 1985; 11-39.

38 Prochaska JO. In search of how people change: applications to addictive behaviours. Am. Psychol. 1992; 9: 1102-14.

39 Glanz K, Patterson RE, Kristal AR, et al. Stages of change in adopting healthy diets: fat, fibre and correlates of nutrient intake. Health Educ. Q. 1994; 21(4): 499-519.

40 Fishbein M, Ajzen I. Belief, Attitude, Intention and Behaviour: An Introduction to Theory and Research. Reading, MA: Addison-Wesley, 1980.

41 Caputo FA, Mattes RD. Human dietary responses to perceived manipulation of fat content in a mid-day meal. Int. J. Obes. 1993; 17: 237-40.

42 Chapelot D, Pasquet P, Apfelbaum M, Fricker J. Cognitive factors in the dietary response of restrained and unrestrained eaters to manipulation of the fat content of a dish. Appetite 1995; 25: 155-76. 
43 Dubbert PM, Johnson WG, Schlundt DG, Montague NW. Influence of caloric information on cafeteria food choices. J. Appl. Behav. Anal. 1984; 17: 85-92.

44 De Graaf C, Drijvers JJMM, Zimmermans NJH, et al. Energy and fat compensation during long-term consumption of reduced-fat products. Appetite 1997; 29: 305-23.

45 Louis-Sylvestre J, Chabert M, Larue-Achagiotis C. Fat content of spontaneous food choice following consumption of fatreduced foods. Appetite 1994; 22: 280-2.

46 Poppit SD, Swann DL. Dietary manipulation and energy compensation: does the intermittent use of low-fat items in the diet reduce total energy intake in free-feeding lean men? Int. J. Obes. 1998; 22: 1024-31.

47 Blundell JE, Burley VJ, Cotton JR, Lawton CL. Dietary fat and the control of energy intake: evaluating the effects of fat on meal size and postmeal satiety. Am. J. Clin. Nutr. 1993; 57 (Suppl.): S772-8.

48 Blundell JE, Lawton CL, Cotton JR, MacDiarmid JI. Control of human appetite: implications for the intake of dietary fat. Ann. Rev. Nutr. 1996; 16: 285-319.

49 Stubenitsky K, Aaron JI, Catt SL, Mela DJ. The influence of nutritional and sensory descriptive information on measures of food selection and acceptance in a restaurant. Appetite 1997; 29(2): 225-65.

50 Köster EP, Beckers AWJM, Houben JB. The influence of health information of the acceptance of a snack in a canteen test. In: Martens M, ed. Flavour Science and Technology. Chichester: Wiley, 1987; 391-8. 